\title{
Strength Characteristics of Mortar Containing Different Sizes Glass Powder
}

\author{
N. Tamanna, N. Mohamed Sutan, I. Yakub and D. T. C. Lee
}

\begin{abstract}
A greater portion of nonrecyclable waste glass is accumulated on landfills creating a serious environmental problem. Recent studies have been carried out to utilize the waste glass in construction as partial replacement of cement. This paper investigates the fineness properties of four sizes glass particles and strength characteristics of mortar in which cement is partially replaced with glass powder in the replacement level with $10 \%, 20 \%, 30 \%$ and $40 \%$. Mortar cubes containing with varying particle sizes in the ranges of $212 \mu \mathrm{m}, 75 \mu \mathrm{m}, 63-38 \mu \mathrm{m}$ and lower than $38 \mu \mathrm{m}$ and in a water to cement ratio 0 f 0.50 and 0.45 have been prepared. Room temperature and relative humidity have been maintained $32^{\circ} \mathrm{C}$ and $90 \%$ respectively during the curing process. Replacement of $10 \%$ cement with glass powder reveals the higher compressive strength at 28 days than other levels of replacement. The reduction in compressive strength increases with the level of cement replacement.
\end{abstract}

Keywords: Waste glass powder, cement replacement, compressive strength, 28days.

\section{INTRODUCTION}

$\mathrm{T}_{\mathrm{e}}^{\mathrm{H}}$ HE generation of waste materials has increased according to the rapid growth of industry and population explosion. The greater portion of these materials do not decompose by itself accumulated on the landfill areas, will remain in the environment for many years, thereby contributing to the environmental problems. The utilization of waste material in construction industries has been increased significantly, in the recent years owing to the short or long term properties of concrete without compromising concrete performance [1]. Waste glass is one such material, which is encouraged for recycling. Theoretically, glass is a $100 \%$ recyclable material; it can be indefinitely recycled without any loss of quality [2]. Nevertheless, the recycling rate of waste glass is quite low compared to the other solid wastes because of expensive cleaning and color sorting cost [3]. Environmental regulations and deficiency of landfill space are also encouraging the use of waste glass in concrete production.Several studies were carried out on the use of waste glass as an aggregate for concrete production in the 1960s. The first practice was conducted by Schmidt and Saia [4], 1963 to the use of glass chips to produced architectural exposed aggregate for concrete.

The effect on mechanical properties of using waste glass in concrete had been studied by many other researchers, including Johnston (1974), Figg (1981)[5]-[6]. Owing to high disposal cost of waste glass and environmental regulation the use of glass as cement concrete aggregates has attracted again under attention of the researchers in the last 20 years [7]-[13]. This aggregate was applied in road construction and also used for production of glass tiles, wall panels, bricks, glass fibre, agriculture fertilizer landscaping reflective beads and tableware [14].

N. Tamanna. is with the Department of Civil Engineering, Faculty of Engineering, Universiti Malaysia Sarawak (UNIMAS), 94300 Kota Samarahan, Sarawak, Malaysia (phone: +60 109712010 ; e-mail: nafisatamanna@yahoo.com).

N. Mohamed Sutan. is with the Department of Civil Engineering, Faculty of Engineering, Universiti Malaysia Sarawak (UNIMAS), 94300 Kota Samarahan, Sarawak, Malaysia ((phone: 082583232 ; e-mail: msnorsuzailina@ feng.unimas.my).

I. Yakub. is with the Department of Chemical Engineering and Energy Sustainability, Faculty of Engineering, Universiti Malaysia Sarawak (UNIMAS), 94300 Kota Samarahan, Sarawak, Malaysia (phone: 08258 3264; e-mail: yibrahim@ feng.unimas.my).

D. T. C. Lee. is with the Department of Civil Engineering, Faculty of Engineering, Universiti Malaysia Sarawak (UNIMAS), 94300 Kota Samarahan, Sarawak, Malaysia (phone: 082583273 ; e-mail: tdelsye@ @eng.unimas.my). 


\section{UNIMAS e-Journal of Civil Engineering: Volume 5, Issue 1}

Alkali silica reaction considered as an extreme barrier that restrains the waste glass utilization [15]. The feasibility of using waste glass as cement replacement was $1^{\text {st }}$ introduced by Patttengil and Shutt [16]. It was examined that if the glass was powder to a particle size of $300 \mu \mathrm{m}$ or smaller, the ASR would not be harmful in concrete production [17]. It can act as a pozzolanic material to react with portlandite in hydrated cement to form C-S-H in increasing strength and durability of concrete because of the high silica content in glass powder [18]-[23]. This paper deals the strength characteristics of mortar containing different sizes of glass powder with different water to cement ratio. Cement is replaced by glass powder at rates varying from 10 to 40 percent. Particle size distribution, morphology and compressive strength are studied and made a comparison with control samples.

\section{MATERIALS AND METHODS}

Raw materials:

Portland cement

Ordinary Portland Cement (OPC) ASTM Type 1 which is manufactured by Cahaya Mata Sarawak Cement Sdn. Bhd (CMS) was used throughout the research, and it confirmed the quality requirements specified in the Malaysian Standard MS 522: Part 1: 1989 Specifications for OPC. The relevant physical properties and chemical composition of the OPC ASTM Type 1 obtained from the manufacturer are shown in tables 1 and 2.

Table 1: Physical properties and chemical composition of ordinary Portland cement

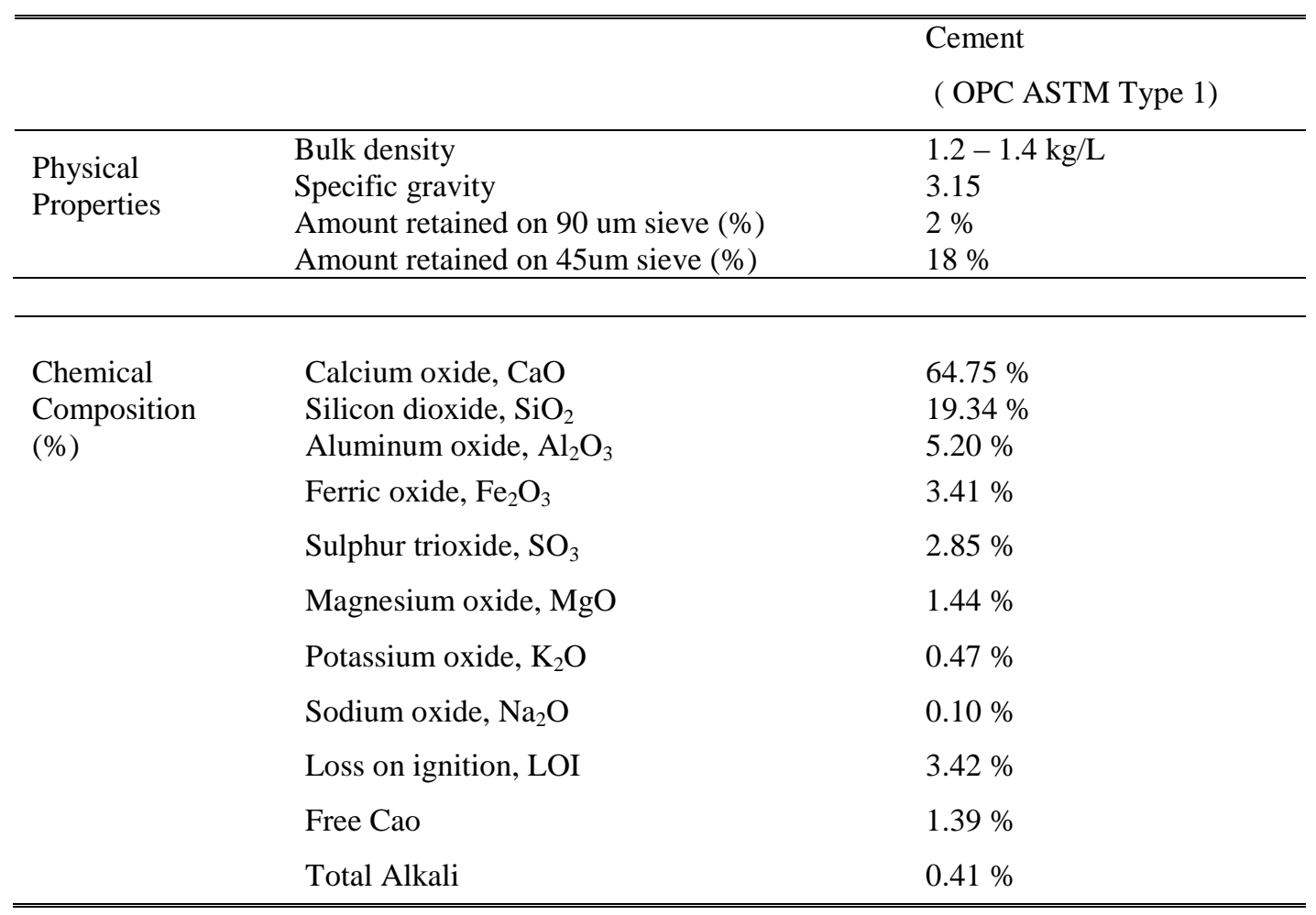




\section{UNIMAS e-Journal of Civil Engineering: Volume 5, Issue 1}

\section{Glass powder}

Waste Glass used in this study was soda-lime clear glass bottles collected from recycle center and from the manufacturer. Glass bottles were cleaned with water to remove paper on the surface and to eliminate contaminations. The glass powder is obtained from the grinding machine (Los Angeles Abrasion Machine) in civil engineering laboratory and subjected to mechanical sieve analysis to get the desired particle size. To study particle size effect, four different sizes are used.

Glass Type 1: Glass powder having particles passing a \#70 sieve (212 micron) and retained on a \#100 sieve (150 micron).

Glass Type 2: Glass powder having particles passing a 100 sieve (150 micron) and retained on a \#200 sieve (75 micron).

Glass Type 3: Glass powder having particles passing a \#200 sieve (75 micron) and retained on a \#400 sieve (38 micron).

Glass Type 4: Glass powder having particles passing a \#400 sieve (38 micron).

\section{Sand and water}

Sand used as a fine aggregate was obtained from Civil Engineering Laboratory, UNIMAS which is free from organic or chemical substance and passing through ASTM sieve no.16 aperture $1.18 \mathrm{~mm}$ sieve. Water used as mixing water was collected from laboratory.

\section{Particle Size Distribution}

The particle size distribution of cement and four sizes glass powder was measured by using CILAS 1090 Laser Particle Size Analyzer.

\section{Scanning Electron Microscope}

In this research, SEM was carried out to analyze the particle size and shape of waste glass powder using Analytical Scanning Electron Microscope (JSM-6390LA) supplied by JEOL Company Limited, Tokyo, Japan. Waste glass powders were spread on a double sided adhesive conductive carbon tape to prevent scattering of loose particles. Then the samples were coated with platinum in argon gas atmosphere at a high vacuum of $30 \mathrm{MPa}$ in order to provide the samples electrically conductive in nature. The photographs, captured at a magnitude of 200 are presented in result and discussion section.

\section{Compressive strength test}

Compressive strength of four type glass powder as cement replacement was investigated in the concrete laboratory. Mortar samples were prepared by glass powder containing $212 \mu \mathrm{m}$ and $75 \mu \mathrm{m}, 75-38 \mu \mathrm{m},<38 \mu \mathrm{m}$ with water to cement ratio 0.50 and 0.45 respectively. Type 1 glass powder was replaced in the level of $10 \%, 20 \%$ \& $30 \%$ by weight casted into $150 \mathrm{~mm}$ X $150 \mathrm{~mm}$ X $150 \mathrm{~mm}$ and type 2,3,4 glass powder were replaced in the level of $10 \%$, $20 \%, 30 \% \& 40 \%$ by weight casted into $50 \mathrm{~mm}$ X $50 \mathrm{~mm}$ X $50 \mathrm{~mm}$ cube. All the samples were cured in the concrete laboratory with average temperature of $32^{\circ} \mathrm{C}$ and relative humidity of $90 \%$.

\section{RESULTS AND DISCUSSION}

\section{Morphology of glass particle under Scanning Electron Microscope}

Scanning electron microscope shows the typical shape of four different sizes of glass powder. Glass powder type 1 which represents $212-150 \mu \mathrm{m}$ exhibit angular shapes but not in uniform sizes. A large number of fine particles present in $212 \mu \mathrm{m}$ glass powder where as angular flaky particles consist in both $75 \mu \mathrm{m}$ and $38 \mu \mathrm{m}$ glass powder. 


\section{UNIMAS e-Journal of Civil Engineering: Volume 5, Issue 1}

Moreover, $38 \mu \mathrm{m}$ glass powder shows more angular shapes than glass powder type 1 and 2 as shown in figure1 (c). Glass powder which is lower than $38 \mu \mathrm{m}$ contains homogeneous angular particles with a sharp edge than any other glass powders, shown in figure 1 (d) that gives similar particle size distribution as Portland cement.

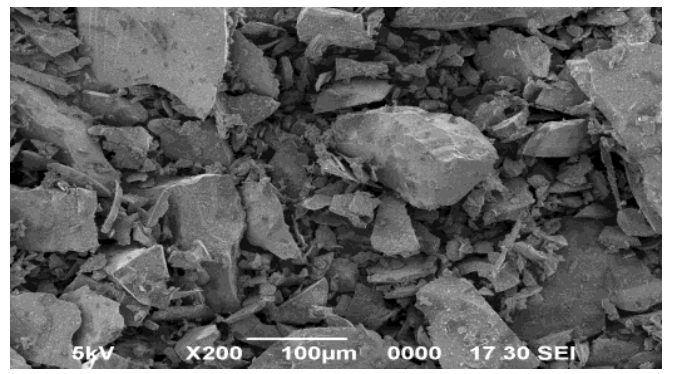

(a)

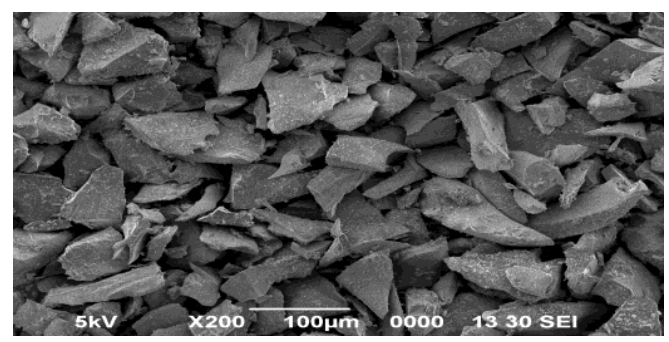

(c)

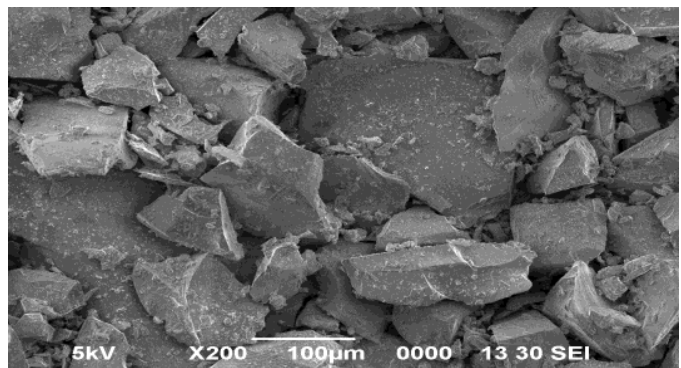

(b)

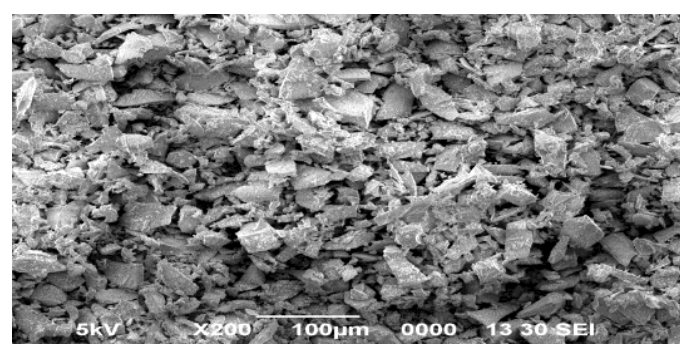

(d)

Figure 1: Shape of glass powder (a) $212-150 \mu \mathrm{m}$ (b) $150-75 \mu \mathrm{m}$ (c) $75-38 \mu \mathrm{m} \&$ (d) $<38 \mu \mathrm{m}$

\section{Particle size distribution}

Figure 2 represents the particle size distribution of ASTM Type 1 portland cement and four sizes glass powder. It can be seen that the glass particles lower than $38 \mu \mathrm{m}$ exhibit almost the same as that of Portland cement. The mean diameter of Portland cement is $21.19 \mu \mathrm{m}$ while the particles lower than $38 \mu \mathrm{m}$ is $21.35 \mu \mathrm{m}$. Portland cement contains about $50 \%$ of particles lower than $18.13 \mu \mathrm{m}$ whereas glass powder contains 17.15 micron. Only one difference is lower than $38 \mu \mathrm{m}$ glass particles maintain about $10 \%$ of particles nearly $4 \mu \mathrm{m}$ where Portland cement maintains $2.79 \mu \mathrm{m}$.

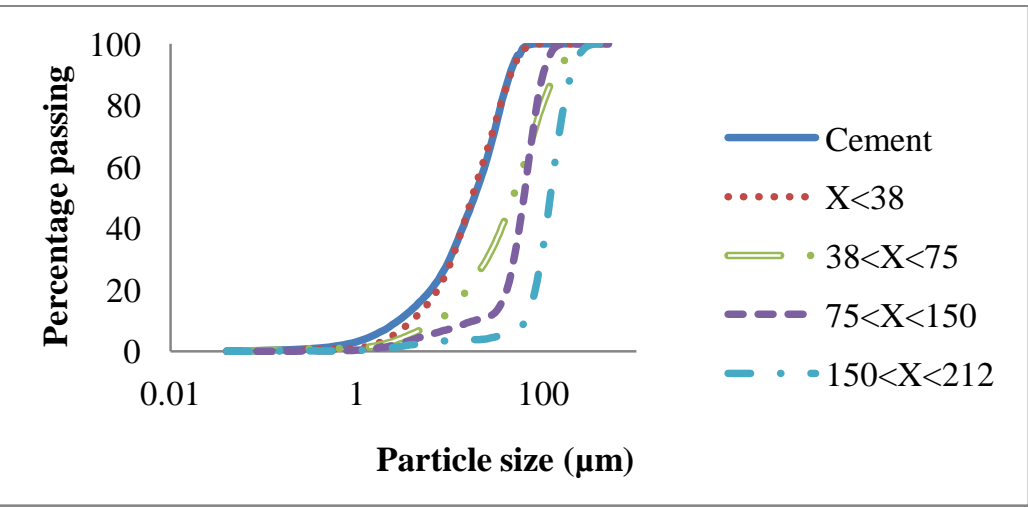

Figure 2: The particle size distribution 
Glass type $3(38<X<75)$ shows a coarser distribution than Portland cement and glass type $4(X<38)$. The particle size distribution of glass type 3 is very similar in mean diameter but slightly finer than glass type $2(75<X<150)$. Glass type 3 keeps up about $10 \%$ of particles finer than $7.50 \mu \mathrm{m}$ on the contrary glass type 2 keeps up coarser than $18 \mu \mathrm{m}$. Glass type $1(150<X<212)$ displays coarser distribution than all type glass and Portland cement wherein $10 \%$ of particles contain higher than 64micron but Portland cement does not.

\section{Compressive strength test of mortar}

The compressive strength of different batches at 28days is shown in figure 3-4. The compressive strength results of $212 \mu \mathrm{m}$ glass powder (type 1) are plotted in figure 3. Control sample reveals the highest compressive strength than different percentage of replacement. Mortar containing $10 \%$ glass indicates slightly lower strength than control sample which is very close to that mortar containing $20 \%$ glass. It can be seen that the reduction in compressive strength increases with the level of cement replacement. The reduction in compressive strength is caused by a reduction in the quantity of cement content available for the hydration process.

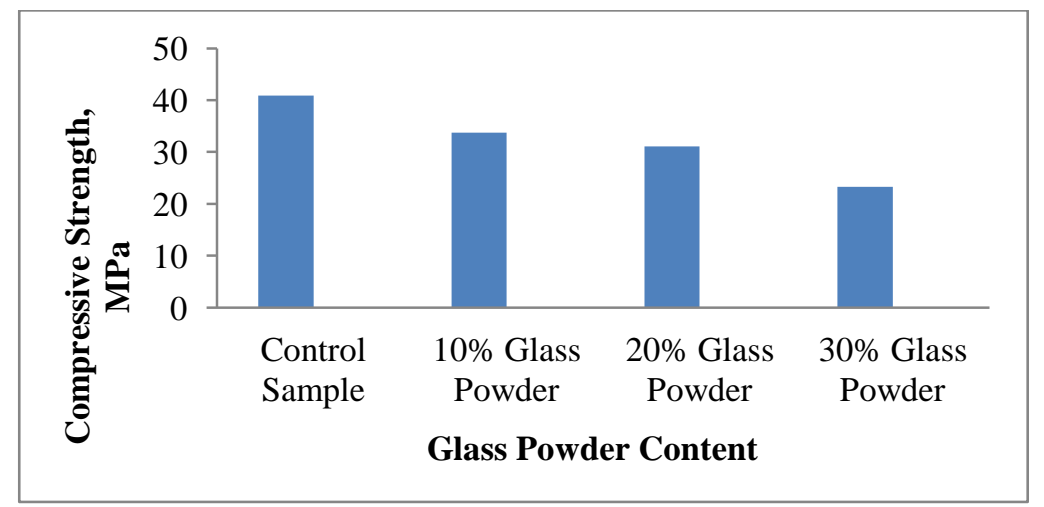

Figure 3: Compressive strength of $212 \mu \mathrm{m}$ glass powder

The compressive strength results of control sample and type 2, 3, 4 glass powder are plotted in figure 4 at 28 days of curing. Glass particles lower than $38 \mu \mathrm{m}$ exhibits higher compressive strength than the control sample at $10 \%$ level of replacement that is confirmed by Khatib et al. [24]. Another $75 \mu \mathrm{m}$ and $75-38 \mu \mathrm{m}$ glass particles show comparatively higher value of strength at $10 \%$ replacement.

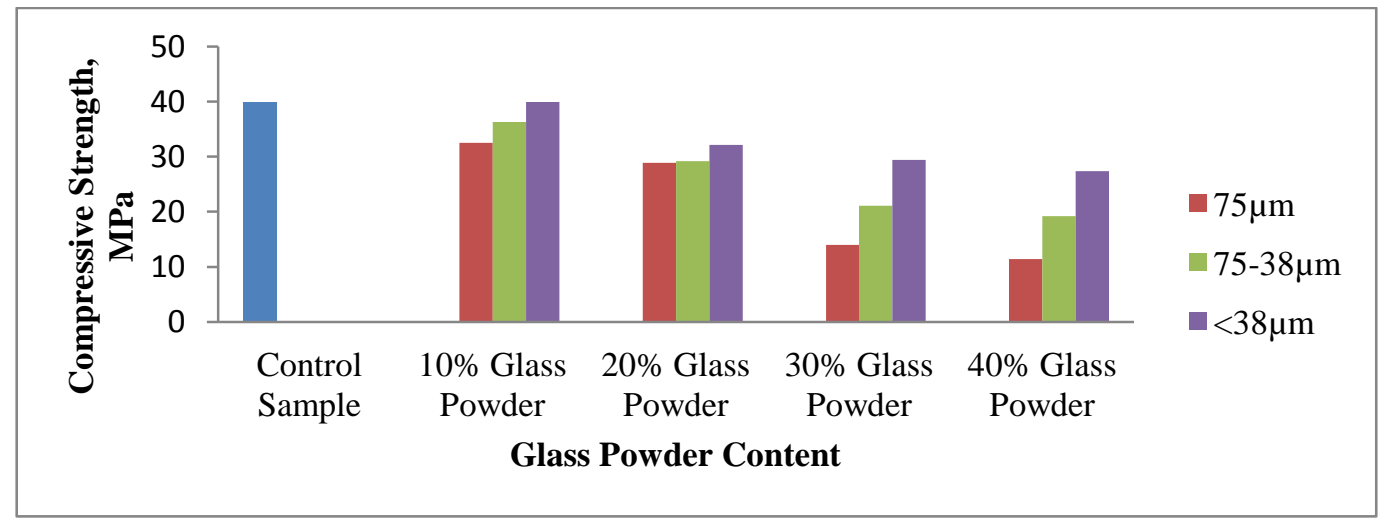

Figure 4: Compressive strength of different sizes glass particles with control sample at 28days

Glass particles lower than $38 \mu \mathrm{m}$ gives the higher result on different percentage than another two types of glass particles. Replacement level at 20\% the $75 \mu \mathrm{m}$ and $75-38 \mu \mathrm{m}$ gives almost the same strength while at 30\% and $40 \%$ replacement shows a large difference between them. Samples with $30 \%$ and $40 \%$ of replacement by glass powder 


\section{UNIMAS e-Journal of Civil Engineering: Volume 5, Issue 1}

show lower strength due to reduction of cement in mortar samples. All other mortar samples show a systematic decrease in strength with the increase of replacement level. It can be seen that compressive strength increases with the decrease of glass particle size.

\section{CONCLUSION}

In the present study, the glass powder can be used as a partial replacement of cement. Replacement of $10 \%$ cement with glass powder reveals the higher compressive strength at 28days than other levels of replacement. Finer size glass particle exhibits comparatively better result than coarser particles. Particle size, finer than $38 \mu \mathrm{m}$ shows almost the same strength as Portland cement, due to the similar particle size distribution. Utilization of waste glass in cement replacement would be beneficial for environment by saving landfill and by reducing $\mathrm{CO}_{2}$ at atmosphere.

\section{ACKNOWLEDGMENT}

The authors acknowledge the research grant provided by Ministry of Education and Universiti Malaysia Sarawak under Fundamental Research Grant (FRGS): FRGS/03(07)/839/2012(73).

\section{REFERENCES}

[1] Patel D., Yadav R.K., Chandak R., "Strength characteristics of pre cast concrete blocks incorporating waste glass powder,"ISCA J. Engineering Sci.,Vol.1(1),68-70,July(2012).

[2] Sobolev K., Turker P., Soboleva S., Iscioglu G., 2006, "Utilization of waste glass in ECO-cement: strength properties and microstructural observations," Waste Management 27 (7), 971-976.

[3] Kiang H.T., Hongjian D., "Use of waste glass as sand in mortar: part I-fresh, mechanical and durability properties," Cement \& concrete composites 35(2013)109-117.

[4] Schmidt A., Saia W.H.F., (1963), "Alkali-aggregate reaction tests on glass used for exposed aggregate wall panal work," ACI Mat. J., 60, 1235-1236.

[5] Johnson C.D., "Waste glass as coarse aggregate for concrete, J. Test. Eval, 2(5), 1974,pp. 344-350.

[6] Figg J.W., (1981), "Reaction between cement and artificial glass in concrete," Proc., Conf. on Alkali-aggregate reaction in concrete, Capetown, South Africa.

[7] Pollery C, Cramer SM, De La Cruz RV. "Potential for using waste glass in portland cement concrete". J Mater Civ Eng 1998;10(4): 210-9.

[8] Topcu IB, Canbaz M. Properties of concrete containing waste glass. Cem Concr Res 2004;34: 267-74. Van Roode M, Douglas E, Hemmings RT. X-ray diffraction measurement of glass content in fly ashes and slags. Cem Concr Res 1987;17(2):183-97.

[9] Meyer C, Baxter S. Use of Recycled Glass for Concrete Masonry Blocks Final Report 97-15. Albany, New York: New York State Energy Research and Development Authority; 1997.

[10] Meyer, C., and Baxter, S., 1998. "Use of recycled glass and fly ash for precast concrete". Rep. NYSERDA 98-18 (4292-IABRIA-96) to New York State Energy Research and Development Authority, Dept. of Civil Engrg. and Engrg. Mech., Columbia University, New York.

[11] Chen CH, Huang R, Wu JK, Yang CC. "Waste E-glass Particles used in cementitious mixtures".Cem Concr Res2006; 36:449-56

[12] Byars EA, Morales-Hernandez B, Zhu HY. "Waste glass as concrete aggregate and pozzolan". Concrete 2004; 38(1):41-4.

[13] Bazant ZP, Zi G, Meyer C. "Fracture mechanics of ASR in concretes with waste glass particles of different sizes". J Eng Mech 2000; 126:226-32.

[14] Reindl J. Report by recycling manager, dane County, Department of Public Works, Madison, USA, August 1998.

[15] Dhir R.K.,Dyer T.D., Tang A., and Cui Y., (2004), "Towards maximizing the value and sustainable use of glass," Concrete for the Construction Industry, 38(1), 38-40.

[16] Pattengill M., and Shutt T.C., (1973), “Use of ground glass as a pozzolan,” Proc., Int. Symp. on Utilization of Waste Glass in Secondary Products, ASCE, Albuquerque, N.M.

[17] Meyer C., Baxter S., Jin W. 1996. Alkali-silica reaction in concrete with waste glass as aggregate. in: K.P. Chong (Ed.), Materials for a New Millennium, Proceedings of ASCE Materials Engineering Conference, Washington, D.C., pp. $1388-1394$

[18] Shao Y, Lefort T, Moras S. Damian Rodriguez. “Studies on concrete containing ground waste glass". Cement and Concrete Research 2000;30(1):91-100

[19] Shayan A, Xu A. "Value-added utilisation of waste glass in concrete". Cement and Concrete Research 2004; 34(1):81-9.

[20] Shi C, Wu Y, Riefler C, Wang H. "Characteristics and pozzolanic reactivity of glass powders". Cement and Concrete Research 2005;35(5):987-93.

[21] Shayan A, Xu A. "Performance of glass powder as a pozzolanic material in concrete: a field trial on concrete slabs". Cement and Concrete Research 2006;36(3):457-68.

[22] Ozkan O, Yuksel I. "Studies on mortars containing waste bottle glass and industrial by-products". Construction and Building Materials 2008;22(6):1288-98.

[23] Taha B, Nounu G. "Properties of concrete contains mixed colour waste recycledglass as sand and cement Replacement". Construction and Building Materials 2008;22(5):713-20.

[24] Khatib J.M., E.M. Negim, H.S. Sohl And N. Chileshe, "Glass powder utilization in concrete production," European Journal of Applied Sciences 4(4): 173-176,2012. 